\title{
Experimental and Simulation Study of Effects in Etched Patch Antenna with Multi Slots
}

\author{
AMBRESH P AMBALGI ${ }^{1}$, SUJATA S K ${ }^{2}$, ARTI VAISH ${ }^{3}$ \\ ${ }^{1}$ Department of Electronics, Mangalore University,Konaje-574199, Mangaluru, Karnataka, INDIA. \\ 2 Department of ECE, GodutaiEngineering collegefor Women, Gulburga-585103. Karnataka, INDIA. \\ ${ }^{3}$ Electronics dept., School of Engineering \& Technology, Ansal University, Gurgaon, Haryana, INDIA.
}

\begin{abstract}
This paper aims for the design and development of a multi slotted novel patch antenna with multiband characteristics. The work focused on designing a patch, feedline with novel multi-slots on the same patch which can be commonly used in wireless applications. In addition, the analysis shows the effects of the improved antenna properties obtained by etching such novel slots on epoxy dielectric substrate using photolithography process. The paper concentrated on the design aspects of the patch antenna with slot dimensions as a function of operating wavelength $(\lambda)$ to get better results. The antennas are implemented with the help of software package V15.4 - Integral Three-Dimension Equation (IE3D) EM simulator. The experimental and simulation findings show the overall required bandwidth of $1120 \mathrm{MHz}$ with a return loss of $-43 \mathrm{~dB}$ achieving a gain of $8.39 \mathrm{~dB}$ with better radiation characteristics.
\end{abstract}

Key-Words: - Simulation, Integral, Miniature, Multiband, Slotted, Axial, Bandwidth.

Received: February 17, 2020 . Revised: September 4, 2020. Accepted: September 22, 2020. Published: October 6, 2020.

\section{Introduction}

Microstrip antenna (MSAs), is one of special category of antenna in RF, microwave signal communication which plays a significant role in the wireless communication application, because of its numerous advantages of microstrip antennas over the normal antenna. Over decades the designing of the low profile antenna for the communication applications was a fundamental area of research. The multi strip antenna is one such[1]. The literature shows the variety of designs of multi-band MSA characteristics with better bandwidth and more than one functional wireless terminal based on orthopolarized concepts [2-10] recently. Single radiators with Multi-band antennas are desirable in most applications [6]. some of them are Bow tie antenna with meandered slot, U-type slot patch antenna for improved percentage bandwidth (BW), slotted microstrip antenna with miniaturized size and circularly polarized nature, $\mathrm{E}$ and $\mathrm{U}$ slotted patch etched dielectric material, circular shape asymmetric slotted MSA, slots of ring on patch having dissimilar designs[11-24]. Some of the common demerits of MSAs are small BW ranging between 1- $2 \%$, minimal gain, least power handling capacity. From the Multiple methods of design the novel slot etched patch with direct strip feeding was found to be rare in survey papers and this method proves to enhance various antenna[25-29] parameters. Improving bandwidth, gain and radiation pattern [30-35] of MSA has been important research challenge in the strip line antenna field. A compact, circularly polarized wideband (CP) squared slot antenna for universal ultra-high-frequency (UHF) handheld reader (RFID) applications is proposed [36]. The antenna is a coplanar waveguide (CPW) fed by a feeding line inverted Z-shaped. Through installing four stubs inside the square slot in diagonal directions and two inverted T-shaped wires, broadband $\mathrm{CP}$ service, large axial ratio bandwidth and good impedance matching is achieved. The impedance bandwidth estimated $<-10 \mathrm{~dB}$ ranges from $706 \mathrm{MHz}$ to $1007 \mathrm{MHz}$ (301 MHz, 35.1 per cent). The 3-dB axial ratio (AR) calculated is $427 \mathrm{MHz}(745-1172$ $\mathrm{MHz}, 44.5$ per cent). The proposed antenna has a 
maximum gain estimated at $4.8 \mathrm{dBi}$. In [37] suggested a novel concept to minimize mutual coupling in circular patch antennas. A circular MIMO antenna with parasitic portion in the dumb-bell form is placed between the two circular patch antennas thus minimizing the mutual coupling. The proposed design has been observed to achieve multi-band characteristics at $3.1 \mathrm{GHz}, 6.2 \mathrm{GHz}$ and $7.7 \mathrm{GHz}$. Impedance bandwidths (IBWs) at the tri-band frequencies are around $90 \mathrm{MHz}, 320 \mathrm{MHz}$, and 540 MHz. A low-profile, dual-band, unidirectional, tag antenna for ultra-high frequency band (UHF) radio frequency (RFID) applications [38]. The antenna consists of a lightweight printed dipole, a 4 x 4 periodic metallic plates surface, and a metallic reflector. The dipole antenna is fed by a modified $\mathrm{T}$ matching network to match the impedance in conjugation matching with UCODE GSM chip. Simulated $\mathrm{S}_{11}<-10 \mathrm{~dB}$ bandwidth are of $840-855$ $\mathrm{MHz}$ and $916-932 \mathrm{MHz}$ and unidirectional radiation with a range of $7.0 \mathrm{~dB}$ and $5.8 \mathrm{~dB}$ at $925 \mathrm{MHz}$ and $845 \mathrm{MHz}$ respectively. The final design with an overall size of $190 \mathrm{~mm} \times 190 \mathrm{~mm} \times 15.8 \mathrm{~mm}(0.532 \lambda \mathrm{x}$ $0.532 \lambda \times 0.044 \lambda$ at $840 \mathrm{MHz}$ ) yields a simulated < $-10 \mathrm{~dB}$ bandwidth of $840-855 \mathrm{MHz}$ and $916-932$ MHz. A novel dual-band co-aperture planar array antenna is proposed [39]. The radiating elements operating at a higher frequency band are grouped and reused for the lower frequency band by adopting the concept of segmented patches. A total of $4 \times 4$ " $\mathrm{H}$ "shaped patches, fed by two independent microstripfeeding networks through rectangular slots, are taken as the radiating elements for a $4 \times 4$ higher-band array antenna, and simultaneously as the radiating elements for a $2 \times 2$ lower-band array antenna. A Ku-band, compact, polarization-reconfigurable, multilayered, wideband antenna is proposed in [40]. Two orthogonal linear polarizations can be realized by switching the ON-OFF state of four $\mathrm{p}-\mathrm{i}-\mathrm{n}$ diodes that are embedded into the polarization-reconfigurable coupling slots. A prototype of the proposed reconfigurable antenna has been fabricated and tested. The measured fractional impedance bandwidth is larger than $22.4 \%$ with the reference of $\left|\mathrm{S}_{11}\right| \leq-10 \mathrm{~dB}$. The measured gain versus frequency is stable and higher than $4 \mathrm{dBi}$ within the operating frequency band. This paper is organized into introduction, design considerations of antenna, results and discussion, conclusion, acknowledgment and references.

\section{1 Article Highlights}

- The novel slots are etched on the patch plane to improve the performance parameters for the proposed antennas by the method of photolithography process. The initial design is carried out using AutoCAD software and later these designs are simulated using IE3D Electromagnetic simulation software for verification.

- The proposed antennas achieved a maximum bandwidth of $1200 \mathrm{MHz}$ with a return loss of -43 $\mathrm{dB}$ (with a gain if $8.39 \mathrm{~dB}$ ) having better radiation broadsided radiation properties.

- The proposed antennas are suitable for wideband wireless application such as RADAR, $\mathrm{X}$ band application, Fixed satellite based services

\section{Design consideration of Novel Multi-Slotted Patch Antennas}

The designed CAD sketch of the Microstrip antenna (MSA) is represented in Fig.1. The equivalent circuit of MSA has inductance $\left(L_{1}\right)$, resistance $\left(R_{1}\right)$ and Capacitance $\left(C_{1}\right)$ connected in parallel with each other and terminated to the ground. Photolithography process is the technique used to fabricate/etch the patch according to the optimized design of CAD sketch. A $50 \Omega$ SMA connector is connected to the microstrip feed line for excitation of the patch. The geometry of conventionalrectangular microstrip antenna (Conventional MSA: C-MSA) is shown inFig.1.The back side of the patch is copper layer acting as a ground plane connected to the base of the SMA connector. The dimensions of the length and width of patch and slots are the order of multiples of wavelengths $(\lambda)$ and fraction of wavelength $(\lambda)$. In the next step, the C-MSA is etched with novel eight multi-slotted patch having octagonal slot, square slot, circular slot on patch and named as Eight Multi-Slotted Patch having Octagonal slot, Square slot, Circular Slot on Patch (EMSPOSCP)backed with ground plane $\left(L_{g} \mathrm{X}\right.$ $W_{g}=40 \times 40 \mathrm{~mm}$ ). The dimensions of various novel slots on the patch surface are factor of wavelength and the octagonal slot dimensions in outside length $(S)$ and its inside side length $(T)$ are $4.30 \mathrm{~mm}$ and $2.30 \mathrm{~mm}$, wide square slot dimensions are $S_{1}, S_{2}=$ $3.48 \mathrm{~mm}$ and narrow square slot are $S_{3}, S_{4}=1.28 \mathrm{~mm}$. The original patch dimensions of $(L x W),\left(L_{t} x W_{t}\right)$ and $\left(L_{f} x W_{f}\right)$ are same as C-MSA. Similarly, as in fig.3 a novel Multi Slotted Patch antenna having Hexagonal slots, Rhombus slots, Square slots on patch (MSPAHRSP) and its dimensions of horizontal and vertical rhombus slot lengths $\left(L_{l}\right.$ and $L_{2}$ ) are $9.6 \mathrm{~mm}$ and $13.8 \mathrm{~mm}$, side length $S L_{l}$ is 6.61 $\mathrm{mm}$ and hexagon slide length $S L_{2}=5.2 \mathrm{~mm}$ respectively. Broad shape slots are etched on MSPAHRSP when compared to narrow shape 
slots since; broader slots are more efficient 1 improving the $\mathrm{BW}$, gain of antenna when compared to narrow slots [25]. The effects and the enhanced properties of patch antenna by etching such novel slots are studied in next section.

\section{3.1 Conventional - rectangular microstrip 3. antenna (C-MSA) characteristics}

The frequency response characteristics of designed C-MSA, EMSPOSCP, MSPAHRSP are experimentally studied on Agilent Technology E8363 model PNA working for $0.10 \mathrm{MHz}-40 \mathrm{GHz}$ frequency range. The C-MSA as in fig. 1 is theoretically designed for $3 \mathrm{GHz}$ frequency. The $10 \mathrm{dBRL}$ frequency response characteristics is studied and measured for 2- $4 \mathrm{GHz}$ frequency band as in Fig.4. The simulation study is also carried out using licensed Mentor Graphics IE3D V.15.4 EM simulation software. Fig. 4 shows the experimental and simulation $-10 \mathrm{~dB}$ frequency response curve of CMSA where it has BW of $2 \%(20 \mathrm{MHz})$ with minimum $\mathrm{RL}$ of $-20 \mathrm{~dB}$ at $3 \mathrm{GHz}$ resonance which validates the theoretical design. It also shows the simulated response where C-MSA resonated for 3.2 $\mathrm{GHz}$ with $\mathrm{BW}=2.8 \%(31 \mathrm{MHz})$ with $\mathrm{RL}=-18 \mathrm{~dB}$. The slight variation in the simulated and experimental frequency resonance is due to the dependent temperature variation of dielectric permittivity material, also due to the effect of $50 \mathrm{ohm} \mathrm{SMA}$ connector and coaxial feed [32]. The variations in the bandwidth can also be seen because the simulated study is done by declaring the parameters in ideal conditions in IE3D EM software and hence experimental bandwidth varies marginally with simulated result. From the radiation pattern plot as shown in fig.5, it is clear that the pattern is linearly polarized with broadsided nature at $3 \mathrm{GHz}$ resonance. The broadside is because of the patch acting as the full resonant element at $3 \mathrm{GHz}$ frequency fed by a microwave fed power connected to SMA (sub miniature A type) connector.

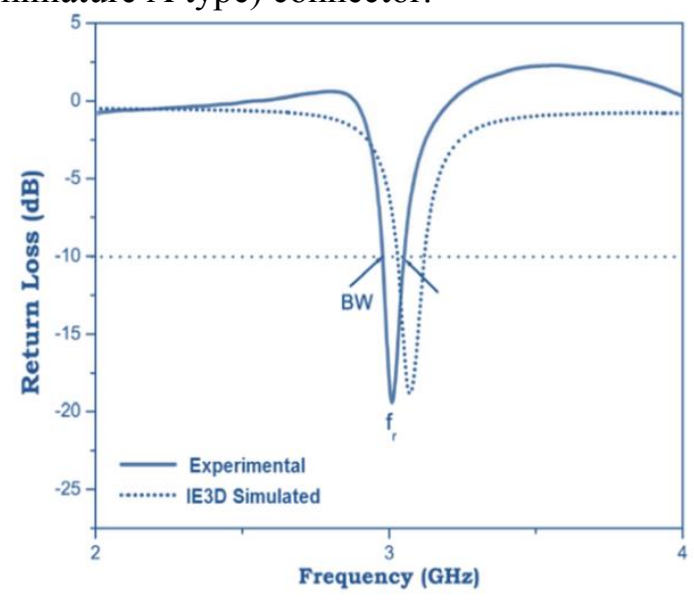

Fig 4. Variation of RL Vs frequency of C-MSA $(3 \mathrm{GHz})$ 


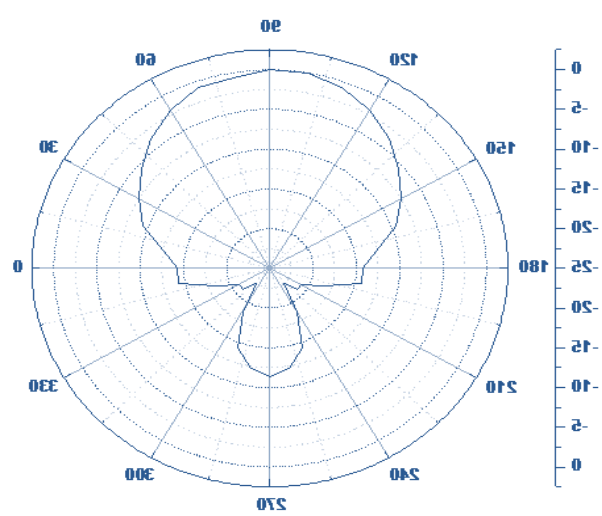

Fig 5. Measured radiation pattern of C-MSA $(3 \mathrm{GHz})$

This patterns makes the antenna to have its coverage range to be broader with less cross polar level and interefernce for desired user based communication applications. The measured half power beam width of $\mathrm{C}-\mathrm{MSA}$ is $43^{\circ}$. The practical gain of C-MSA if founnd to be $2.1 \mathrm{~dB}$. Such antenna (C-MSA) can be useful for indoor communication applications.

\subsection{Eight Multi-Slotted Patch having Octagonal slot, Square slot, Circular Slot on Patch (EMSPOSCP)}

The Eight Multi-Slotted Patch having Octagonal slot, Square slot, Circular Slot on Patch (EMSPOSCP) as shown in fig. 2 is tested practically and simulated.The IE3D simulated and experimental frequency response graph of EMSPOSCP is shown in Fig.6 and is measured for $2-12 \mathrm{GHz}$ frequency band. The experimentally resonance for EMSPOSCP are $2.8 \mathrm{GHz}(\mathrm{RL}=-18 \mathrm{~dB}), 6.2 \mathrm{GHz}(\mathrm{RL}=-17 \mathrm{~dB})$ and 9.8 $\mathrm{GHz} \quad(\mathrm{RL}=-43 \quad \mathrm{~dB})$ respectively. Measuerd bandwidths (BW of EMSPOSCP 1 are found to be $11 \%, 48.51 \%(1200 \mathrm{MHz})$ and $29 \%$ with wide bandwidth i.e. for $2.0 \mathrm{GHz}-12 \mathrm{GHz}$ band. The simulated resonance of EMSPOSCP are $2.8 \mathrm{GHz}$ $(\mathrm{RL}=-20 \mathrm{~dB}), \quad 6.1 \mathrm{GHz}(\mathrm{RL}=-33 \mathrm{~dB})$ and $9.6 \mathrm{GHz}$ $(\mathrm{RL}=-36 \mathrm{~dB})$. EMSPOSCP has achieved practical gain of $8.39 \mathrm{~dB}$.Compared to C-MSA, EMSPOSCP has shown improvement in $\mathrm{BW}$ which is due to new type of slots etched on the patch which provides elongated surface patch current excited on the patch width and length making antenna to resonate over wide bandwidth [32] with better RL. Fig. 7 shows that EMSPOSCP exhibited linearly polorized broadside pattern with $57^{\circ}$ half power beamwidth. The gain is improved to $8.31 \mathrm{~dB}$ due to the current path excitation resulting into decrease of qfactor of antenna [33]. This antenna has its applications in communication band

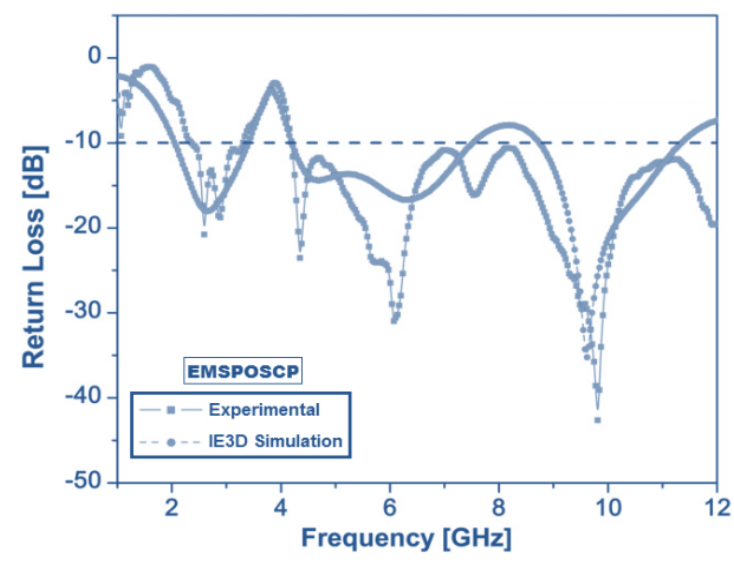

Fig 6. Variation of RL Vs frequency of EMSPOSCP

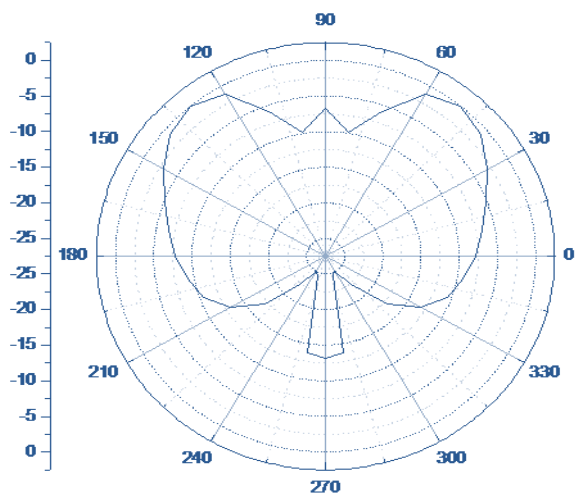

Fig 7.2D pattern of EMSPOSCP at $2.8 \mathrm{GHz}$

\subsection{Multi-Slot Patch Antenna with Hexagonal slot, Rhombus slot, Square slot on patch (MSPAHRSP)}

The experimentally measured and IE3D simulated result of $-10 \mathrm{~dB}$ RL characteristics of MSPAHRSP for $2-12 \mathrm{GHz}$ is as shown in Fig. 8. As per fig.8, MSPAHRSP resonated for triple band of frequencies i.e., $f_{1}, f_{2}$ and $f_{3}$ having different impedance bandwidth $\mathrm{BW}_{1}, \mathrm{BW}_{2}$ and $\mathrm{BW}_{3}$ respectively. The calculated bandwidth at each operating band are found to be $\mathrm{BW}_{1}=12.51 \%(310 \mathrm{MHz}), \mathrm{BW}_{2}=16.51 \%(480 \mathrm{MHz})$ and $\mathrm{BW}_{3}=20.21 \%(531 \mathrm{MHz})$ respectively with better RL. The minimum RL at $\mathrm{BW}_{1}$ is $-29.51 \mathrm{~dB}$ which appears at $f_{1}=1.8 \mathrm{GHz}, \mathrm{RL}$ at $\mathrm{BW}_{2}$ is $-43 \mathrm{~dB}$ at $f_{2}=6.3 \mathrm{GHz}$ and $\mathrm{RL}$ at $\mathrm{BW}_{3}$ is $-45 \mathrm{~dB}$ at $f_{3}=9.4$ GHz. The simulated resonant frequencies of MSPAHRSP are $f_{1}=2.4 \mathrm{GHz}\left(\mathrm{BW}_{1}=10.51 \%, \mathrm{RL}=\right.$ - $11.06 \mathrm{~dB}), f_{2}=5.7 \mathrm{GHz}\left(\mathrm{BW}_{2}=19.51 \%, \mathrm{RL}=-26\right.$ $\mathrm{dB})$ and $f_{3}=9.4 \mathrm{GHz}\left(\mathrm{BW}_{3}=25.21 \%, \mathrm{RL}=-34\right.$ $\mathrm{dB}$ ). Hence by adding slots (wider in size) on patch, not only multi bands are achieved but also 
enhancement upto $531 \mathrm{MHz}$ of bandwidth at $\mathrm{BW}_{1}$ is achieved when compared to the bandwidth of $\mathrm{BW}_{1}$ of C-MSA.

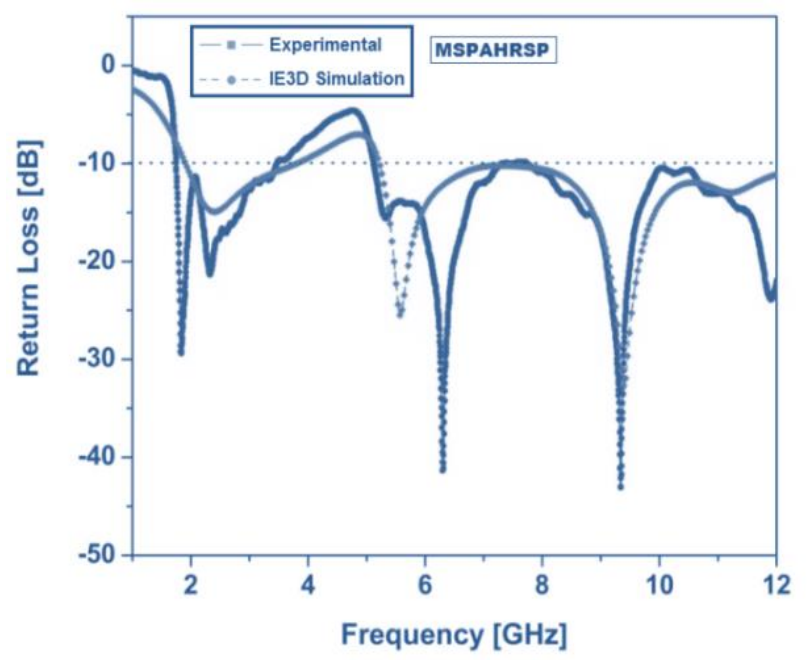

Fig 8. Variation of RL Vs frequency of MSPAHRSP

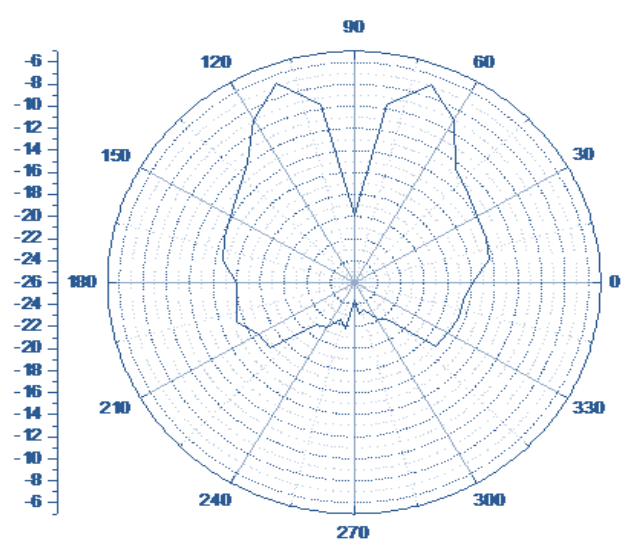

Fig 9. 2D pattern of MSPAHRSP at $9.4 \mathrm{GHz}$

Fig. 9 shows the 2D Radiation characteristics of MSPAHRSP measured at only one resonant frequency. From this figure, it is clear that MSPAHRSP has broadsided radiation with linear polarization characteristics. Measured half power
Table 1. Measured antenna characteristics

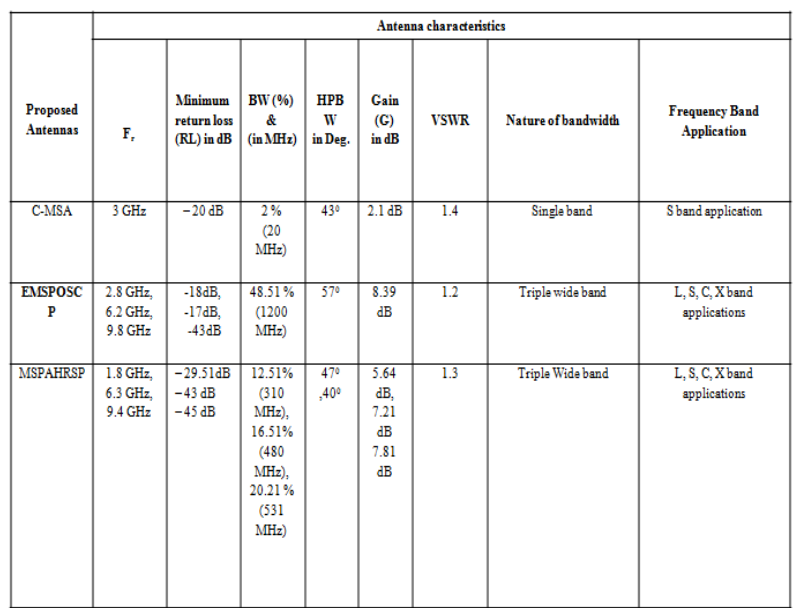

beam width of MSPAHRSP is found to be $47^{\circ}, 40^{\circ}$. The maximum gain of MSPAHRSP measured in $\mathrm{BW}_{1}, \mathrm{BW}_{2}$ and $\mathrm{BW}_{3}$ are found to be $5.64 \mathrm{~dB}, 7.21 \mathrm{~dB}$ and $7.81 \mathrm{~dB}$. This kind of antenna suits for wireless communication application in $\mathrm{C}, \mathrm{X}$ band frequency range. Among all the proposed antennas EMSPOSCP remains as the best option for wireless applications as given in table 1 . The table 2 show the study of few comparisons made with the research findings related to survey paper.

Table 2. Comparative study with few literature survey papers

\begin{tabular}{|c|c|c|c|}
\hline Sl.no & Literature survey & \begin{tabular}{|l|} 
Literature survey \\
Results
\end{tabular} & $\begin{array}{l}\text { Present results obtained } \\
\text { this study }\end{array}$ \\
\hline 1 & In Survay paper no.37(2019) & $\begin{array}{c}\text { A maximum bandwidth } \\
\text { of } 540 \mathrm{MHz} \text { is } \\
\text { obtained }\end{array}$ & $\begin{array}{l}\text { Our study has shown } \\
\text { a } 1100 \mathrm{MHz} \text { bandwidth }\end{array}$ \\
\hline 2 & In Survey paper no.38 (2019) & \begin{tabular}{|c|} 
A bandwidth are of \\
$840-855 \mathrm{MHz}$ and \\
$916-932 \mathrm{MHz}$ and \\
unidirectional radiation \\
with a range of $7.0 \mathrm{~dB}$ \\
and $5.8 \mathrm{~dB}$ at $925 \mathrm{MHz}$ \\
and $845 \mathrm{MHz}$ \\
respectively
\end{tabular} & $\begin{array}{c}\text { A gain of } 8.31 \mathrm{~dB} \text { is } \\
\text { obtained. }\end{array}$ \\
\hline 3 & In Survey paper no.39(2020) & \begin{tabular}{|c|} 
A validation model is \\
fabricated, and \\
measured results \\
demonstrate a working \\
bandwidth of $8.8 \%$ \\
from 5.4 to $5.9 \mathrm{GHz}$ \\
and another working \\
bandwidth of $7.3 \%$ \\
from 13.2 to $14.2 \mathrm{GHz}$ \\
\end{tabular} & $\begin{array}{c}\text { A bandwidth of } 48.51 \% \text { is } \\
\text { obtained with this novel } \\
\text { slots technique on patch } \\
\text { plane. }\end{array}$ \\
\hline 4 & In Survay paper no.40 (2020) & $\begin{array}{c}\text { The measured } \\
\text { fractional impedance } \\
\text { bandwidth is larger } \\
\text { than } 22.4 \% \text { with the } \\
\text { reference of } \mathrm{S}_{\mathrm{S}} \mathrm{I} \mid \leq-10 \\
\text { dB. The measured gain } \\
\text { versus frequency is } \\
\text { stable and higher than } 4 \\
\text { dBi within the } \\
\text { operating frequency } \\
\text { band }\end{array}$ & $\begin{array}{l}\text { A bandwidth of } 48.51 \% \\
\text { with } 8.31 \mathrm{~dB} \text { gain is } \\
\text { achieved in this proposed } \\
\text { study }\end{array}$ \\
\hline
\end{tabular}




\section{Conclusion}

This paper presented the results in the form of experimental and IE3D simulation study of novel multislots on the patch surface which has shown a signifying improvement in the antenna characteristics. Proposed antenna has multi-bands for the communication based application in wireless domain (RADAR, X band application, fixed satellite based services). EMSPOSCP has attained bandwidth of $1200 \mathrm{MHz}$ with return loss of $-43 \mathrm{~dB}$. The measured gain was also found to be $8.39 \mathrm{~dB}$. The improved antenna characteristics with multiband nature are achieved through the process of optimizing the dimension of patch length, width as well as slot dimensions keeping a dependent. The improvements in bandwidth and gain are due to the addition new type of multislots on patch surface.

\section{Acknowledgments}

This work is supported by VGST, KSTEPs, Government of Karnataka, India for funding under research grants for scientist faculty (RGS/F) scheme to study and work in the area of Microstrip antennas for super high frequency (SHF) band range.

\section{Fundıng}

Vision Group of Science \& Technology (VGST), Karnataka Science \& Technology Promotion Society (KSTePS), Govt. of Karnataka (VGST/KSTePs: GRD No.731) has supported and funded this work under RGS/F research grant.

\section{Conflict Of Interest}

The declaration is made to thereof that the author's donot have any conflict of interest.

\section{References}

[1] R.Garg , P. Bhartia, I. J. Bhal, A. Ittipiboon, Microstrip Antenna Design Handbook. Artech House, Boston, 2001.

[2] C. Chulvanich, J. Nakasuwan, N. Songthanapitak, N. Ansntrasirichai T. Wakabayashi, Design of narrow slot antenna for dual frequency, PIERS Online, Vol. 3. No.7, 2007, pp. 1024-1028.

[3] Y. J. Wang, C. K. Lee, Design of dual-frequency microstrip patch antennas and application for IMT-2000 mobile handsets, Progress In Electromagnetics Research, Vol.83, 2002, pp. 265-278.
[4] S. V. Shynu, G. Augustin, C. K. Anandan, P. Mohanan, K. Vasudevan, Design of compact reconfigurable dual frequenc microstrip antennas using varactor diode, Progress In Electromagnetics Research, Vol. 60, 2008, pp. 197-205.

[5] Rastogi, Alok Kumar, GazalaPravin, Shanu Sharma, Comparative Study of Rectangular and E-Shaped Microstrip Patch Antenna Array for X-Band Applications, In Advanced Computing and Communication Technologies, Springer, Singapore, 2019.

[6] Usha, Tamanna Yeasmin, Swad Al Nahiyan, Md Hasanuzzaman Sagor, Design and Analysis of Hybrid Feed Array for Metamaterial Loaded Microstrip Patch Antenna. IEEE International Workshop on Antenna Technology (iWAT-2019), 2019, pp. 101-104.

[7] Ghannad, AmirhosseinAlizadeh, Mohsen Khalily, Pei Xiao, Rahim Tafazolli, Ahmed A. Kishk, Enhanced Matching and Vialess Decoupling of Nearby Patch Antennas for MIMO System, IEEE Antennas and Wireless Propagation Letters, Vol.8, No.6, 2019, pp.1066-1070.

[8] T. Archevapanich, J. Nakasuwan, N. Songthanapitak, N. Ansntrasirichai, Wakabayashi, E-shaped slot antenna for WLAN applications, PIERS Online, Vol.3, No.7, 2003, pp. 1119-1123.

[9] Verma, Anurag, Arun Kumar, Saptarshi Gupta, Design and Performance Analysis of Round Micro-Strip Patch Antennae $2 \times 4$ Array for $2.40 \mathrm{GHz}$ Wireless Demands, In Applications of Computing, Automation and Wireless Systems in Electrical Engineering, Springer-Singapore, 2019, pp. 759771.

[10] G. Mayhew-Rydgers, J. W. Avondale, J. Joubert, New feeding mechanism for annular-ring microstrip antenna, Electronics Letters, Vol. 36, pp. 605-606, 2000.

[11] N. S. Nurie, R. J. Langley, Input impedance of concentric ring microstrip antennas for dual frequency band operation including surface wave coupling, IEE Proceedings, Vol.137, No.6, 1990, pp. 331-336.

[12] I. Misra and S. K. Chowdhury, Study of impedance and radiation properties of a concentric microstrip triangularring antenna and its modeling techniques using FDTD method, IEEE Trans. Antennas Propagation, Vol. 46. No.4, 2003, pp. 531-537.

[13] S. I. Latif and L. Shafai, Dual-layer square-ring (DLSRA) for circular polarization, IEEE Antennas and Propagation Society International Symposium. 2A, 2005, pp.525-528.

[14] R. Gargand V. S. Reddy, Edge feeding of microstrip ring antennas, IEEE Trans. Antennas Propagation, Vol.51, No. 8, 2003, pp.1941-1946.

[15] P. M. Bafrooei and L. Shafai, Characteristics of single and double-layer microstrip square-ring antennas, IEEE Trans. Antennas Propagation, Vol.47, No. 10, 1999, pp.1633-1639,

[16] S. Behera and K. J. Vinoy, Design of dual frequency microstrip ring antennas, IEEE International Symposium on Microwaves ISM, Vol.08, 2008, pp. 277-281.

[17] R. Hopkins and C. Free, Equivalent circuit for the microstrip ring resonator suitable for broadband materials characterization, IET Microwaves Antennas Propagation, Vol. 2, No.1, 2008, pp. 66-73.

[18] S.L S Yang, A. A. Kishk and K. F. Lee, Frequency reconfigurable $U$-slot microstrip patch antenna, IEEE Antennas Wireless Propag. Lett., Vol.7, 2008,pp.127-129.

[19] S.H. Wi, J. M. Kim, T. H. Yoo, H. J. Lee, J. Y. Park, J. G. Yook and H. K. Park, Bow-tie-shaped meander slot antenna for $5 \mathrm{GHz}$ application, Proc. IEEE Int. Symp. Antenna Propag., Vol. 2, 2002, pp.456-459.

[20] R. Chair, C. L. Mak, K. F. Lee, K. M. Luk and A. A. Kishk, Miniature wide-band half $U$-slot and half E-shaped patch 
antennas. IEEE Trans. Antennas Propag., Vol.53, 2005, pp. $2645-2652$.

[21] G. F. Khodaei, J. Nourinia and C. Ghobadi, A practical miniaturized $U$-slot patch antenna with enhanced bandwidth, Progress In Electromagnetics Research B, Vol. 3,2005, pp. 47-62.

[22] N. Misran, M. N. Shakib, M. T. Islam and B. Yatim, Design analysis of a slotted microstrip antenna for wireless communication, Proc. of World Academy of Science Engineering and Technology, Vol.37, 2009, pp.448-450.

[23] Prabhu, T., S. ChenthurPandian, and E. Suganya, Contact Feeding Techniques of Rectangular Microstrip Patch Antenna for $5 \mathrm{GHz} \mathrm{Wi}$-Fi, 5th IEEEInternational Conference on Advanced Computing \& Communication Systems (ICACCS-2019), 2019, pp. 1123-1127.

[24] Nasimuddin, Zhi Ning Chen and Xiamming Qing, Asymmetric-Circular Shaped Slotted Microstrip Antenna for Circular Polarization, IEEE Transactions on Antennas and Propagation, Vol.58,No. 12, 2010, pp.3821-3828.

[25] Nasimuddin, ZhiNing Chen and Xiamming Qing, Slotted Microstrip Antenna for Circular Polarization with Compact Size, IEEE Antenna and Propagation Magazine, Vol. 55, No. 2, 2013,124-137.

[26] Krishna, Ch Rama, ChPrabhuAnand, and D. Durga Prasad, Design of S-Shaped Micro-strip Patch Antenna for Ka Band Applications, In International Conference on Intelligent Computing and Communication Technologies, 2019, pp. 260-268. Springer Singapore.

[27] R. E. Munson, Conformal microstrip antennas and microstrip phased arrays, IEEE Trans. Antennas Propagate., Vol. 22, 1974, pp. 74-78.

[28] Q. E. Howell, Microstrip Antennas, IEEE Trans. Antennas Propagat., Vol.23, 1975, pp. 90-93.

[29] Singh, Rohan, Arun Kumar Singh, Rabindranath Bera and BansibadanMaji, Optimization of Microstrip Patch Array Antenna for Gain Enhancement, In Advances in Communication, Devices and Networking. SpringerSingapore, 2019, pp. 123-132.

[30] Midasala, Vasujadeviand P. Siddaiah, Microstrip patch antenna array design to improve better gains, Procedia Computer Science, Vol. 85, 2016, pp. 401-409.

[31] K. R. Carver, J. W. Mink, Microstrip antennas technology. IEEE Trans. Antennas Propagate., Vol. 29, 1981, pp. 2-24.

[32] R. J. Maillouxet al., Microstrip array technology. IEEE Trans. Antennas Propagate., Vol.29, 1981, pp. 25-37.

[33] Jieh - SenKuo, Gui - Bin Hsieh, Gain enhancement of a circularly polarized equilateral-triangular microstrip antenna with a slotted ground plane, IEEE Trans. on Antennas Propagate., Vol.51, No.7, 2003, pp. 1652-1656.

[34] S. Rhee and G. Yun, CPW fed slot antenna for triplefrequency band operation, Electronics Letters, Vol. 42, No.17, 2006, pp. 952-953.

[35] Gh. Z. Rafi and L. Shafai, Wideband V-slotted diamondshaped microstrip patch antenna, Electronics Letters, Vol. 40, No.19, 2004, pp. 1166-1167.

[36] Waleed A. Ahmed, Quanyuan Feng, Zhuang Xiong and Muhammad K. Khan, A Compact Universal Antenna Design for UHF RFID Handheld Reader, Progress In Electromagnetics Research C, Vol.91, 2019, pp. 173-183.

[37] Kommana Vasu Babu and Bhuma Anuradha, Analysis of Multi-Band Circle MIMO Antenna Design for C-Band Applications, Progress In Electromagnetics Research C, Vol.91, 2019, pp. 185-196.

[38] Son Xuat Ta, Thi Ngoc Hien Doan, Van Khang Nguyen, Khac Kiem Nguye Chien Dao-Ngoc, Low-Profile, DualBand, Unidirectional RFID Tag Antenna Using
Metasurface, Progress In Electromagnetics Research C, Vol. 93, 2019, pp. 131-141.

[39] Jie Wu, Cong Wang, Yong Xin Guo, Dual-Band CoAperture Planar Array Antenna Constituted of Segmented Patches, IEEE Antennas and Wireless Propagation Letters. Vol. 19, No,2, 2020, pp. $257-261$.

[40] Zhuofu Ding, Runjun Xiao, A Ku-Band, Compact, Polarization-Reconfigurable, Multilayered, Wideband Antenna: A proposed design with high mechanical stability, IEEE Antennas and Propagation Magazine.Vol. 62, No.1, 2020,pp. 23-33.

\section{Creative Commons Attribution License 4.0 (Attribution 4.0 International, CC BY 4.0)}

This article is published under the terms of the Creative Commons Attribution License 4.0 https://creativecommons.org/licenses/by/4.0/deed.en US 